\title{
Analysis of the relationship between performance measures and sale price among Angus bulls from two different bull providers
}

\author{
C. Zack Hileman \\ West Virginia University
}

Follow this and additional works at: https://researchrepository.wvu.edu/etd

\section{Recommended Citation}

Hileman, C. Zack, "Analysis of the relationship between performance measures and sale price among Angus bulls from two different bull providers" (2007). Graduate Theses, Dissertations, and Problem Reports. 2518.

https://researchrepository.wvu.edu/etd/2518

This Thesis is protected by copyright and/or related rights. It has been brought to you by the The Research Repository @ WVU with permission from the rights-holder(s). You are free to use this Thesis in any way that is permitted by the copyright and related rights legislation that applies to your use. For other uses you must obtain permission from the rights-holder(s) directly, unless additional rights are indicated by a Creative Commons license in the record and/ or on the work itself. This Thesis has been accepted for inclusion in WVU Graduate Theses, Dissertations, and Problem Reports collection by an authorized administrator of The Research Repository @ WVU. For more information, please contact researchrepository@mail.wvu.edu. 
Analysis of the relationship between performance measures and sale price among Angus bulls from two different bull providers
C. Zack Hileman

Thesis submitted to the Davis College of Agriculture, Forestry, and Consumer Sciences at West Virginia University in partial fulfillment of the requirements for the degree of

Master of Science in Animal and Nutrition Sciences

\author{
Eugene E. Felton, Ph.D., Committee Chairperson \\ Paul E. Lewis, Ph.D. \\ John E. Warren, Ph.D.
}

Department of Animal and Nutritional Science

\author{
Morgantown, West Virginia \\ 2007
}

Keywords: Bull, Performance, Sale price, Model

Copyright 2007 C. Zack Hileman 


\begin{abstract}
Analysis of the relationship between performance measures and sale price among Angus bulls from two different bull providers

C. Zack Hileman

The objective of this study was to determine the relationships of sale price to EPD, Angus Dollar Value Indexes, and actual measurements among Angus bulls of two different seedstock bull providers. Data were obtained from Gardiner Angus Ranch, Ashland, Kansas, for years 2000-2006 on 815 Angus bulls and from the Wardensville bull test, Wardensville, West Virginia, for years 2001-2005 on 357 Angus bulls. Expected progeny differences (EPD) for birth weight (BW EPD), weaning weight (WW EPD), yearling weight (YW EPD), maternal milk (MM EPD), yearling height (YH EPD), scrotal circumference (SC EPD), intramuscular fat (IMF EPD), ribeye area (REA EPD), and rib fat (RBFT EPD) were obtained along with Angus Dollar Value Indexes for Weaned Calf Value (\$W), Feedlot Value (\$F), Grid Value (\$G), and Beef Value (\$B). Actual measurements for average daily gain (ADG), rump fat (Rmpft), rib fat (Ribft), ribeye area (REA), intramuscular fat (IMF), adjusted yearling weight (AdjYW), and bull sale price were obtained as well. Data from Gardiner Angus Ranch were used as a means of comparison between a state bull test station and an established elite seedstock provider.
\end{abstract}

Keywords: Bull, Performance, Sale price, Model 


\section{Acknowledgements}

The past two years at West Virginia University have been a very enjoyable, educational experience. The knowledge that I have gained and the people I have met have truly broadened my horizons.

I would like to thank several people who have been extremely helpful to me and my education. First and foremost, I thank my family for their support in all aspects of my life. It is obvious, to me, that my accomplishments would not have come without their support.

Next, I thank my committee as their guidance made this project possible. I especially appreciate the freedom that I was given to develop my project. In addition, Mr. Phil Osborne, Mr. Jim Pritchard, and Dr. Keith Inskeep provided assistance throughout the project. I am grateful for all they did.

Gardiner Angus Ranch, Ashland, Kansas and Dr. Bill Beal, Virginia Tech provided me with the opportunity to utilize data from the Gardiner Angus program. The Gardiner family should be commended for their extensive data collection and attention to detail. I thank the Gardiner family and Dr. Bill Beal for providing these data.

In the past two years, I have had the opportunity to be a teaching assistant under Dr. John Warren. I truly enjoyed that experience and benefited greatly from the assistantship that accompanied the position. It truly was an extraordinary experience. 


\section{List of Tables}

Table 1 Ultrasound Adjustments for Age and Weight of Angus Bulls and Heifers . 41

Table 2 Ultrasound Age of Dam Adjustments for Angus Bulls and Heifers........... 42

Table 3 Average Angus Bull Comparisons ........................................................ 43

Table 4 Gardiner Angus Bull Data - Simple Statistics ................................... 44

Table 5 Wardensville Angus Bull Data - Simple Statistics ............................. 45

Table 6 Analysis of Variance - Gardiner Data............................................ 46

Table 7 Analysis of Variance - Price Categories - Gardiner Data...................... 47

Table 8 Analysis of Variance - Wardensville Data ........................................... 48

Table 9 Analysis of Variance - Price Categories - Wardensville Data ................. 49

Table 10 Detailed Analysis of Variance - Wardensville Data............................... 50

Table 11 Detailed Analysis of Variance - Price Categories - Wardensville Data... 51

Table 12 Analysis of Variance - Forward Selection - Gardiner Data ....................... 52

Table 13 Analysis of Variance- Forward Selection - Wardensville Data ................. 53

\section{Table of Contents}

ABSTRACT
Acknowledgements
List of Tables




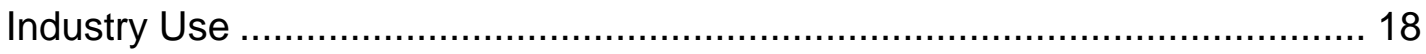

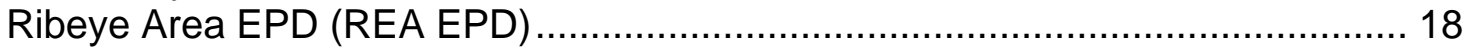

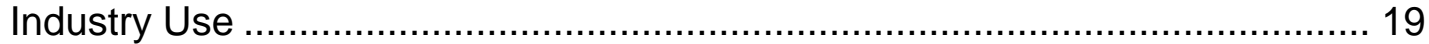

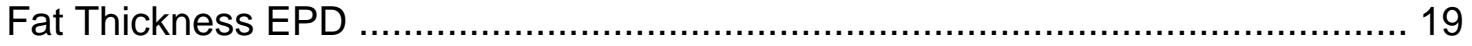

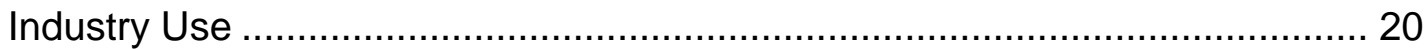

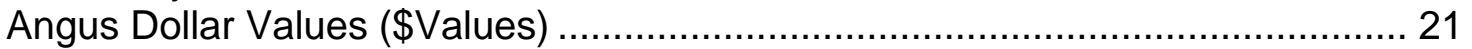

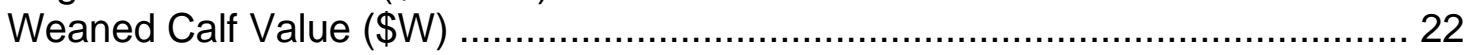

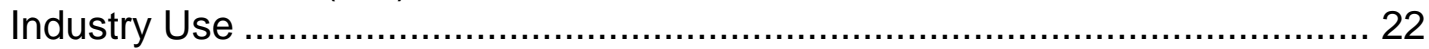

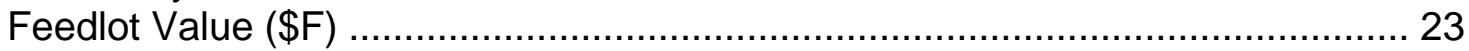

Grid Value (\$G)

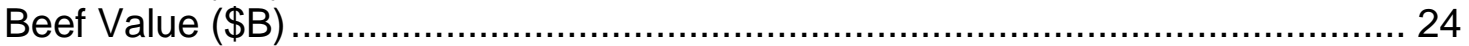

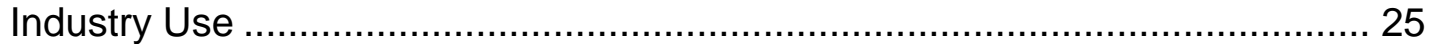

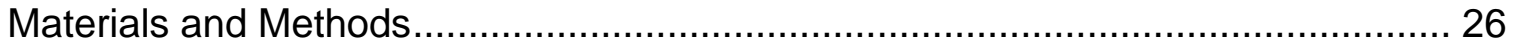

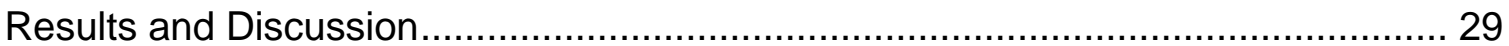

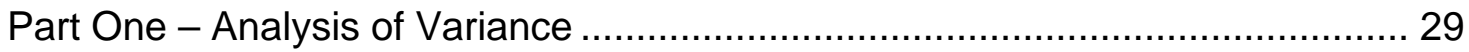

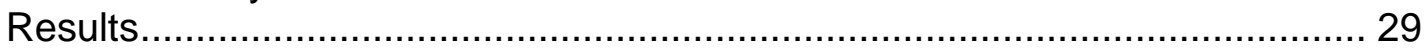

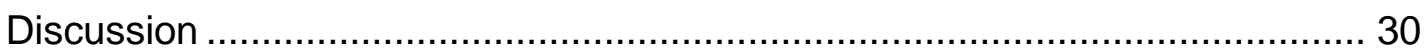

Part Two - Wardensville Detailed Analysis of Variance .................................... 32

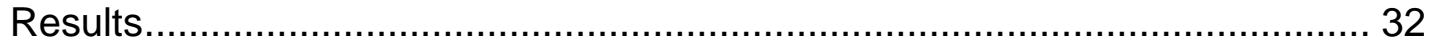

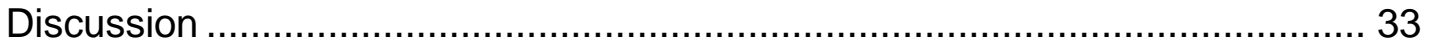

Part Three -Analysis of Variance - Forward Selection- ................................. 34

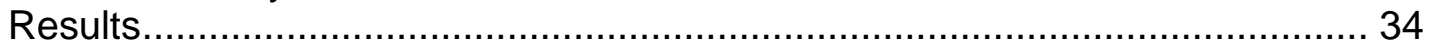

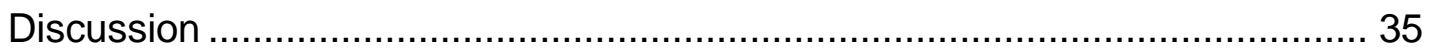

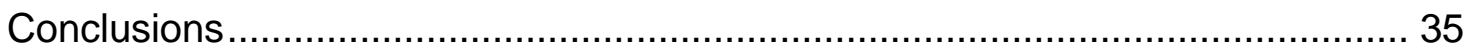

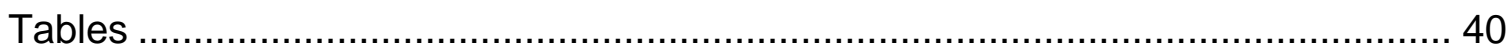

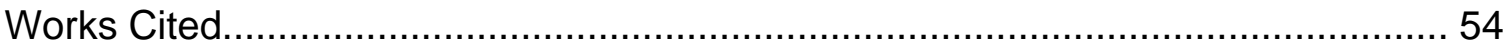




\section{Review of Literature}

\section{United States Beef Industry Overview}

As of January 1, 2007, beef cow numbers, in the United States, were over 32.89 million head reflecting a 0.3 percent decrease from January 1, 2006 (NASS, USDA, 2007). The ability to raise calves that perform well is important. Major aspects that affect calf performance are genetic potential and environment. Based upon the U.S. cow inventory, strong demand exists for breeding age bulls to sire offspring.

The beef industry changes based upon performance of offspring, and consumer demands and preferences (Marshall, 1994; Lamb et al., 1998; Purcell, 1998). The sire transmits fifty percent of his genotype in every calf that he sires, therefore genetic change is made in a commercial operation most effectively through the sire's genetics. During the last half-century, advances have been made that allow more accurate selection for genetic potential. Notably, the introduction of performance measures via sire evaluation tests have allowed bull buyers to select bulls that are more likely to perform in regard to the criteria they deem useful.

In 2006, there were 762,880 beef operations in the United States with managers who make decisions to reach their respective genetic goals (NASS USDA, 2007). Trends in the beef industry tend to shape or alter the characteristics of the average beef animal. Since the 1970's, the industry has 
seen numerous changes ranging from the influence of Continental European breeds to the dietary and health concerns of consumers (Lorenzen et al., 1993). Single trait selection for growth, specifically during the 1970s, resulted in cattle that were larger framed. Lorenzen et al. stated that since that time, cattle have been fed to heavier weights with the same degree of subcutaneous fat and with less marbling, resulting in lower quality grades. In the past few decades, consumer demands also have influenced the average beef animal. The first National Beef Quality Audit, in 1990, found that beef had too much external fat, was too tough, and too inconsistent to remain competitive in the meat market. However, the audit of 2000 indicated that beef demand was on the rise for the first time in 25 years. Much of this change can be credited to producers addressing consumer demands. The preliminary 2005 National Beef Quality Audit found that the percentage of choice and prime carcasses rose from 51percent in 2000 to 56.1 percent in 2005. Additionally, the percentage of prime carcasses rose from 2.0 percent in 2000 to 2.9 percent in 2005 . These changes in proportions of choice and prime changes tend to correlate positively with consumer satisfaction (Neely et al., 1998). Much of this change can be attributed to producers' shift in genetic selection of both bulls and female replacements.

The 2000 National Beef Quality Audit also researched the carcass characteristics of the average beef slaughter animal. The audit showed that the average carcass had a yield grade of $3.0(S D=0.9)$, a quality grade of Select ${ }^{85}$, fat thickness of $1.2 \mathrm{~cm}(\mathrm{SD}=0.5 \mathrm{~cm})$, hot carcass weight of $356.9 \mathrm{~kg}(\mathrm{SD}=42.7$ $\mathrm{kg})$, ribeye area of $84.5 \mathrm{~cm}^{2}\left(\mathrm{SD}=10.8 \mathrm{~cm}^{2}\right)$. The majority of the carcasses 
(96.6\%) were of A-maturity. While the average beef carcass had improved from the 1995 audit, there is more improvement to be made. Most notably, a higher average quality grade would enhance consumer satisfaction. This, coupled with lower yield grades would represent cattle with the ability to store fat as marbling rather than excess external fat. A realistic goal for the beef industry would be an average quality grade of middle Choice and an average yield grade of 2.5. A lesson from the poultry and pork industries can be applied to the beef industry as well. By producing a more uniform product, the beef industry could offer consumers a more predictable product. This would most likely increase the beef industry's percentage of the meat market.

\section{Bull Sales}

There tends to be a pyramid shaped structure in the beef cow/calf industry. The top (smallest percentage) consists of elite purebred producers, the middle is composed of seedstock providers, and the bottom (highest percentage) is composed of commercial producers. Elite producers ultimately tend to provide genetics for all producers below them on the pyramid. Seedstock producers influence their herds with genetics from elite producers and sell their genetics to other seedstock producers as well as commercial producers. Commercial producers tend to market their cattle through the food chain as well as retaining females for replacements. In the United States, bulls are offered for sale by seedstock providers (includes elite producers) through numerous marketing 
avenues. Private breeder auctions, bull test stations, private treaty sales and breed association auctions are different avenues to market breeding age bulls. A private breeder's auction sale is simply a situation in which a seedstock breeder offers their bulls for sale at public auction to the highest bidder. A bull test station combines bulls from many different seedstock breeders, develops them in the same environment, and offers them for sale at public auction to the highest bidder. Advantages and disadvantages exist for private breeder sales as well as bull test stations. Private breeder sales can offer bulls that were bred and developed based upon the specific philosophy of the provider. However, many performance measures (i.e. weight ratios, gain ratios, etc.) can be compared only among the contemporaries in the specific herd. In contrast, bulls from different seedstock providers with different breeding philosophies and genetics can be compared among one another as post-weaning contemporaries at a bull test station. The American Angus Association considers only bulls that were raised together from birth to be true contemporaries. However, significant comparisons can be made when bulls are managed as post-weaning contemporaries in a bull test. While each beef operation may require unique genetics, each bull offers differences in terms of genetic potential. Therefore, it is up to producers to determine the strengths and weaknesses of their cow herds and purchase new genetics to complement their individual situations. 


\section{Performance Measures}

Performance programs, based on individual animal measurements, began to flourish in the 1960s. Prior to 1960, the Fort Keogh Livestock and Range Research Laboratory in Miles City, Montana, along with other research institutions, began collecting performance measures in breeding cattle (Chvosta, 2001). In 1968, the Beef Improvement Federation (BIF) was founded and began to develop guidelines for performance measurements. In 1971, they adopted guidelines for evaluating breeding potential. During the early years, significant progress was made for various performance measures. In addition to actual measurements of performance, expected measurements are calculated as well. Several different names for expected measurements (such as Expected Breeding Values (EBV) or Breeding Values (BV)) were used during the early years of performance testing. It was not until around 1988, however, that the term expected progeny difference (EPD) was used (Chvosta, 2001). Expected Progeny Differences are used to predict the genetic potential of an animal as a parent. Expected Progeny Differences from two animals of the same breed reflect relative differences between each animal's offspring if they were mated to similar animals of the same breed (Greiner, 2002). Expected Progeny Differences are expressed in the units of measure that are relevant to each of the traits. The EPD is calculated and expressed either plus or minus based upon the breed average for the individual trait.

Accompanying each EPD is a measure of accuracy. The EPD accuracy predicts possible change from the actual EPD. Interim EPD values are 
calculated based upon parents' pedigrees and, if available, the calf's own performance measures. Twice each year, the American Angus Association updates each animal's EPD profile. Measures collected from an animal's own performance and performance of its offspring is used to adjust each EPD. As more data are gathered, accuracy of EPD's is increased. Throughout their productive years, the EPD profiles of sires and dams become more accurate. This tends to sort breeding animals based on their performance and the performance of their offspring.

\title{
Pedigrees and Industry Usage
}

\begin{abstract}
A bull's pedigree is a lineage of ancestry. Through breed associations, each registered animal's pedigree is retained in a database that is built upon as breeders register offspring. Seedstock breeders use pedigrees to breed for offspring that fit their performance goals and the demands of their customer market. Typically in the beef industry, seedstock breeders tend to be much more concerned with pedigrees when compared to commercial cattlemen. Breeders seeking to increase the accuracy of matings tend to seek breeding animals with more accurate EPD profiles throughout their lineage.
\end{abstract}




\section{Average Daily Gain (ADG)}

Average Daily Gain is a performance measurement typically taken on bulls that are offered for sale. Usually, bulls are fed a grain-based ration for a period of time prior to being sold. Feeding trials are typically performed to compare growth and carcass ultrasound performance. Feeding trials at bull tests vary significantly in length based upon factors such as the type of ration fed and the preferences of buyers and sellers. However, usually bull tests range from 80140 days. This tends to be long enough for the bulls to exhibit differences in growth performance and carcass characteristics as assessed by ultrasound, while minimizing the negative impacts of overly fat bulls. Brown et al. (1991) showed that a 112 day test length is adequate to determine growth characteristics of bulls in postweaning feedlot performance tests. Bulls are weighed prior to and following the feeding trial, and an average daily gain is calculated. As well, each bull's ADG is expressed as a ratio in order to compare performance among bulls in the feeding trial. Average daily gain is simply an indication of a bull's ability to convert nutritional inputs to body weight. While this measurement is useful, it does not account for differences in mature weight or relative efficiency of the bull. Arnold et al. (1991) showed that in Hereford bulls, there is a genetic correlation of 0.74 between ADG and mature weight. Therefore, selecting for higher ADG will typically result in cattle with larger mature weights. 


\section{Industry Use}

Data on ADG are used by producers to determine how bulls performed when compared to other bulls in the feeding trial. Typically, bulls with higher ADGs are more desirable as their performance is a prediction of their progeny's performance. Progeny that convert feed to gain quickly provide feedlot operators a greater opportunity for profit. Simply, the faster an animal can convert feed to gain, the sooner the animal is ready for slaughter, and the sooner the feedlot operator can market the animal (Fox et al., 2001). Faster growing cattle do not necessarily equate to higher quality slaughter animals. For example, continental breeds of cattle historically gain faster and offer more desirable yield grades than British breeds. However, continental breeds historically yield carcasses with lower quality grades when compared to British breeds. Nevertheless, by reducing days on feed and increasing turnover, operators of feedlots profit from fast growing cattle.

\section{Calving Ease Direct (CED)}

Calving Ease Direct, measured in percentage of unassisted births, is an EPD that predicts the difference in calving difficulty of sires when they are bred to first-calf heifers. A higher Calving Ease Direct EPD predicts that the sire will produce smaller calves that will be delivered easier than a sire with a lower 
Calving Ease Direct EPD. Calving Ease Direct is a more direct estimate of calving difficulty while birth weight EPD is an indirect estimate. Gutierrez et al. (2007) reported that Calving Ease Direct has a high negative correlation $(-0.604)$ with birth weight EPD in the Asturiana de los Valles beef breed of Northern Spain. The National Angus Cattle Evaluation (2007) reported that the heritability of Calving Ease Direct is 0.18 while there tends to be a strong negative correlation $(-0.76)$ with birth weight.

\section{Industry Use}

Calving Ease Direct is potentially significant in terms of reducing dystocia in first calf heifers, especially when used in conjunction with Birth Weight EPD. A bull with a high Calving Ease Direct EPD will have calves that, on average, are born easier. This can be attributed not only to birth weight, but also to shape of the head, neck, and shoulder of the calf (Nugent et al., 1991). Calves that have a larger head, neck, and shoulders will typically be more difficult to be born and most likely will be from a bull with a low calving ease direct EPD. 


\section{Birth Weight EPD (BW EPD)}

Birth weight EPD (BW) is an estimate of the birth weight that a sire will transmit to his offspring. Expressed in pounds ( $+/$ - breed average), it is predicted by the average of the bull's sire's and dam's birth weight EPD along with an adjustment for the bull's actual birth weight. Known as an interim EPD, it is calculated by combining the sire and dam EPDs along with a Mendelian sampling effect. This results in an accuracy of $0.20-0.30$. The Mendelian sampling effect predicts how the calf's own genetic value deviates from its parents. If the actual birth weight of the calf is unknown, the interim EPD can be calculated from only the sire and dam EPDs. However, the resulting EPD will have a lower accuracy at 0.05. The National Angus Cattle Evaluation (2007) reports that the heritability of BW is 0.42 .

\section{Industry Use}

Birth weight EPD is an increasingly popular tool for bull buyers to distinguish bulls that will reduce dystocia in their herds. Especially since the introduction of continental breeds during the mid-1900s, emphasis on birth weight EPD has increased dramatically. Continental sires introduced during the mid-1900s tended to cause tremendous dystocia problems in English-based herds in the United States (Laster et al. 1973). Selecting bulls with Birth Weight EPDs slightly lower than breed average is common practice for breeding replacement heifers, while using bulls with above 
breed average Birth Weight EPDs on mature cows is common practice (Anderson and Bellows, 1967; Laster et al., 1973).

\section{Weaning Weight EPD (WW EPD)}

Weaning weight EPD (WW) is a performance measure, expressed in pounds (+/-breed average), that estimates the sires ability to transmit preweaning growth when compared to other animals within the breed. As with birth weight EPD, it is calculated by averaging the weaning weight EPDs of the sire and dam, and adjusting for the individual performance of the calf using the Mendelian sampling effect mentioned earlier. Weaning weight EPD is adjusted to 205 days of age at weaning. Though the dam's ability to milk is influential in a calf's weaning weight, its effects are not directly reflected in this EPD. Rather, there is a Maternal Milk EPD that accounts for this. The National Angus Cattle Evaluation (2007) reports that the heritability estimate of WW is 0.20 . As well, there tends to be a positive relationship (0.15) with post-weaning gain (PG).

\section{Industry Use}

Throughout much of the United States, producers tend to market their calves by weight when they are weaned (typically 5-9 months of age). Therefore, weaning weight EPD is of importance. A larger weaning 
weight EPD characterizes sires of calves that will grow heavier prior to weaning when compared to calves born from sires with a lower weaning weight EPD. However, single trait selection for larger weaning weight EPDs tends to increase both birth weights and frame size (Koch et al., 1994). Heavier birth weights tend to cause dystocia in females and larger frame scores tend to result in cattle that require more nutritional inputs. Thus, both can be economically detrimental to the cattleman (Ferrell et al., 1985).

\section{Yearling Weight EPD (YW EPD)}

Yearling weight EPD, expressed in pounds (+/- breed average), is an indicator of a sire's ability to transmit growth to a year of age to his offspring. Yearling weight EPD is adjusted to 365 days of age, and is an indicator of a sire's ability to transmit yearling growth in the feedyard. The American Angus Association does not report a direct heritability estimate for yearling weight EPD; however, they estimate heritability of postweaning gain to be 0.20 . As well, there tends to be a fairly strong positive correlation (0.54) with yearling height EPD, and a positive relationship (0.29) with scrotal circumference (National Angus Cattle Evaluation, 2007). 


\section{Industry Use}

Yearling weight EPD is a significant growth indicator used in selecting bulls. As with weaning weight, selecting solely on yearling weight EPD will tend to increase birth weights (Koch et al., 1994). The effects of single trait selection on growth were described above.

\section{Yearling Height EPD (YH EPD)}

Yearling height EPD is a predictor, in inches of hip height (+/- breed average), of an animal's ability to transmit yearling height to their offspring. Hip height is the measurement used for frame score; therefore, yearling height EPD is a frame selection tool. The National Angus Cattle Evaluation (2007) reports that the heritability estimate for yearling height is 0.45 .

\section{Industry Use}

Yearling height is an important factor in terms of producing offspring. Seedstock providers have become more and more reliant on this EPD since it was introduced in the 1970 s as a frame selection tool. Selecting for yearling height EPD can be used to make smaller framed herds larger, and vice versa (Beef Sire Selection Manual, 2000). 


\section{Scrotal Circumference (SC EPD)}

Scrotal circumference EPD, represented in centimeters (+/- breed average), is an indicator of a sire's ability to transmit scrotal size to his offspring. Larger scrotal circumferences offer several advantages. Bull's with larger scrotal circumferences have the ability to produce and store a larger volume of sperm; therefore, they have the potential to service more cows (Elmore et al., 1975). As well, scrotal circumference is correlated negatively with the age the sire's daughters reach puberty. Therefore, selecting sires with larger scrotal circumference EPD tend to result in heifer offspring that reach puberty earlier (Moser et al., 1996). The National Angus Cattle Evaluation (2007) reports that the heritability estimate of scrotal circumference is 0.43 .

\section{Industry Use}

Scrotal circumference EPD, when combined with the actual scrotal circumference of the bull, is a useful selection tool. Seedstock providers use this EPD to produce bulls with larger scrotal circumferences for their customers, while commercial cattlemen use the EPD to select bulls with larger scrotal circumferences to use as herd sires. 


\section{Maternal Milk EPD (MM EPD)}

Maternal milk EPD is a sire's genetic contribution to milk and mothering ability as expressed by his daughters. Simply, maternal milk is the maternal contribution to weaning weight. Therefore, the maternal milk EPD is expressed in pounds of weaning weight of a bull's grandprogeny based upon the milking ability of the bull's daughters. The National Angus Cattle Evaluation (2007) reports the heritability estimate for maternal milk to be 0.14 .

\section{Industry Use}

Maternal milk EPD should be used knowledgeably by producers wishing to maximize preweaning growth. Selecting for milk EPDs that are too high will result in daughters that require more nutritional inputs to maintain their body condition and rebreed. In contrast, selecting for milk EPDs that are too low will result in daughters that require less nutritional input and retain their body condition well; however, they will not contribute as much to their offspring's weaning weight. In a study done using Brangus cows, selecting increased genetic merit for milk production increased forage dry matter intake (DMI) during early lactation (Johnson et al., 2003). Therefore, selection for maternal milk EPD requires that producers be knowledgeable of their nutritional resources as well as the milking ability of their cow herd. 


\section{Ultrasound Measurements and Adjustments}

All ultrasonographic measurements utilized in American Angus Association genetic evaluation are taken at identical locations by certified ultrasound technicians. Ultrasonographic measurements take into account the age at scanning and weight of the animal. Weight is taken within seven days of when ultrasonographic data are collected. The American Angus Association accepts ultrasound measurements collected on bulls between the ages of 320440 days of age. As well, each animal's scan weight is adjusted for its age of dam (AOD). Below, from Wilson et al., 2000, is a list of formulas used to adjust all ultrasonographic measurements, accounting for the animal's age, weight, and for the age of its dam (see Table 1 and 2):

Animal gain, lbs/day = (scanning weight - actual weaning weight $) /$ (animal age at scanning).

365-day scanning weight, lbs = actual scanning weight + (365 - animal age)*animal gain.

AOD, 365 day scanning weight, lbs $=365$-day scanning weight + (adjustment factor from Supplement Table A)

365-day \% IMF (bulls), \% = Actual \% IMF + (365 - animal age) * .003591.

AOD, 365-day \% IMF, \% = 365-day \% IMF + (factor from Supplement Table B).

AOD, 365-day ribeye area (bulls), $\mathrm{in}^{2}=$ Actual ribeye measure $+(A O D$, 365-day scanning weight - scanning weight) * 006197.

AOD, 365-day 12-13th rib fat thickness, in. = Actual 12-13th rib fat thickness + (AOD, 365-day - scanning weight) * .0002952. 
Wilson et al., 2000 showed that adjusting scanning weight for effects of $A O D$, is sufficient correction for the external fat and ribeye measures. However, they found that AOD effects on \% IMF in yearling Angus bulls were small, but significant and showed definite trends as cows mature. Therefore, the AOD adjustment factors to be used for \% IMF measures in Angus records will be to subtract .09 and .13 from bulls and heifers, respectively, out of 2-year-old cows, and.04 and .07 from bulls and heifers out of 3-year-old cows. No AOD \% IMF adjustments will be made to records from calves out of 4 -year old and older cows (Wilson et al., 2000).

\section{Ultrasound Intramuscular Fat EPD (IMF EPD)}

Intramuscular fat of the ribeye muscle is measured via ultrasound as percent of the longissimus dorsi muscle between the $12^{\text {th }}$ and $13^{\text {th }}$ ribs. Values are adjusted to one year of age based upon the formulas mentioned previously and used to calculate EPD estimates for a sire's progeny. The actual measurement of intramuscular fat is related to the quality grade scale, while the intramuscular fat EPD is transformed to a decimal scale. The National Angus Cattle Evaluation (2007) reports the heritability estimate for ultrasound \%IMF EPD as 0.31 , and that this trait tends to be correlated negatively $(-0.04)$ with ultrasound REA EPD and positively (0.22) with ultrasound fat EPD. 


\section{Industry Use}

Intramuscular fat EPD has become an increasingly popular selection tool for commercial producers who retain ownership of their calf crop through the feedyard. These producers are paid on a grid-based system stressing carcass characteristics, so a greater return can be achieved by using bulls with higher intramuscular fat EPDs. Many other traits represent profit in the beef industry as well, so single trait selection for intramuscular fat EPD should not be practiced. For example, a calf with an average birth weight and average intramuscular fat is much more profitable than a calf that was too large to be delivered but had the potential to have a high percentage of intramuscular fat.

\section{Ribeye Area EPD (REA EPD)}

Ribeye area is measured on the longissimus muscle between the $12^{\text {th }}$ and $13^{\text {th }}$ ribs of yearling animals via ultrasound, and adjusted to one year of age. Based upon phenotype, bulls will typically have the largest ribeye areas with steers and heifers following respectively. The National Angus Cattle Evaluation (2007) reports that the heritability estimate for REA EPD is 0.38 , and that it tends to correlate positively (0.18) with ultrasonographic FAT EPD. 


\section{Industry Use}

Ribeye area EPD, as with \% intramuscular fat EPD, has become an increasingly popular EPD, as a result of the grid-based pricing system. The 2000 National Quality Beef Audit reported that average carcass ribeye area was $84.5 \mathrm{~cm}^{2}\left(13.1 \mathrm{in}^{2}\right)$ with a standard deviation of $10.8 \mathrm{~cm}^{2}$ $\left(1.67 \mathrm{in}^{2}\right)$. In most cases, a larger ribeye area represents a more desirable carcass. Therefore, selecting for larger ribeye area EPDs is typically ideal. However, when carcass weights are over 900-950 pounds, carcasses are discounted for having ribeye areas that are too large (Burdine et al., 2002). Therefore, over-selecting for ribeye area EPD could potentially have detrimental effects on profit. Typically, ribeye areas between 12 to 15 square inches are preferable to steak cutters and chefs (Sweeter, 2005). This allows the product to be cut and prepared consistently. However, there are conflicting data, Sweeter et al., 2005 showed that retail customers preferred steaks with ribeye areas up to 18 square inches.

\section{Fat Thickness EPD}

Fat thickness EPD, expressed in inches and adjusted with the formulas previously mentioned, is measured via ultrasound at the $12^{\text {th }}$ rib and between the hook and pin bone on the hip. This EPD is actually a weighted average of 60 percent of the rib fat measurement and 40 percent of the rump fat measurement. 
The National Angus Cattle Evaluation (2007) reports that the heritability estimate for FAT EPD to be 0.39 .

\section{Industry Use}

Typically, because fat thickness EPD correlates with carcass fat thickness, selecting for lower fat thickness EPDs tends to be more desirable from a yield grade standpoint. However, over-selecting for decreased fat thickness EPD can result in decreased carcass quality and females with poor fleshing ability. Lamb et al. (1990) reported that selecting against ultrasound backfat thickness in Hereford bulls would be expected to decrease intramuscular fat, therefore possibly reducing palatability and tenderness of the meat. Lamb et al. (1990) reported a genetic correlation of 0.206 between fat thickness and marbling. However, Wilson et al. (1993) concluded that selection in the Angus breed to reduce external fat can be made without reducing marbling. Wilson et al. (1993) reported a heritability of -0.13 between marbling score and fat thickness. Therefore, based upon available research, there are conflicting data regarding the association between external and internal fat. In terms of fleshing ability of milking females, dams with minimal external fat have lower energy stores to potentially convert to milk. Therefore, there is potential when selecting for less external fat to create a female that requires more nutritional inputs. In most instances, the intramuscular fat 
and ribeye area EPD's are selected much more intensely when compared to fat thickness EPD.

\section{Angus Dollar Values (\$Values)}

The American Angus Association introduced \$Values as a means of multitrait selection for both commercial and seedstock producers. In order to assist producers in making breeding decisions, the American Angus Association has introduced Weaned Calf Value (\$W), Feedlot Value (\$F), Grid Value (\$G) and Beef Value (\$B) as bioeconomic values, expressed in dollars per head. Angus \$Values are simply indices that combine both the animal's genetics and industryrelated economics. As with EPDs, variation in \$Values between animals indicates expected differences in the progeny if random mating is assumed. Therefore, \$Values can be used only when comparing individuals of the same breed. These $\$$ Values are sensitive to changes in industry-related factors that are used to calculate the index such as the economic effects of quality and yield grades. Accuracy of the EPD's used to calculate the \$Values is another point of consideration. For example, an animal with low accuracies of its EPDs may have more desirable \$Values than an animal with more accurate EPDs. However, the potential for greater deviation from the calculated $\$ V$ alue is quite possible when accuracy of the EPD is lower. 


\section{Weaned Calf Value (\$W)}

The Weaned Calf \$Value combines four main areas relevant to preweaning growth of the calf. These include birth weight, weaning weight, maternal milk, and mature cow size; EPDs for each are calculated by the American Angus Association. This index accounts for economic variables relevant to preweaning growth of the calf, including base calf price, cow/heifer mix, cow weight, and feed energy cost. For example, an increase in base calf price would increase Weaned Calf Value, while an increase in feed energy cost would decrease Weaned Calf Value. These assumptions are made using the following resources: National Research Council (NRC), US Meat Animal Research Center (USMARC), Cattle-Fax, Standardized Performance Analysis (SPA) and university cow-calf budgets, and the American Angus Association performance database.

\section{Industry Use}

\$Values are relatively new to the beef industry and have emerged through the American Angus Association as a means of preventing single trait selection as well as potentially simplifying the selection process for commercial cattlemen. Weaned Calf Value combines all aspects important to commercial cattlemen who market their calves at weaning. Therefore, selecting for Weaned Calf Value should be beneficial to those 
producers. However, EPDs for individual traits should still be analyzed to assure that each trait lies within the producer's acceptable range.

\section{Feedlot Value (\$F)}

Feedlot Value (\$F) estimates postweaning merit and incorporates both Weaning Weight EPD and Yearling Weight EPD along with interrelationships between the two and economic factors. Typical feedlot gain value, feed consumption and cost differences are used in the final calculations, along with a standard set of industry values for days on feed, ration costs and cash cattle price. For example, standard industry values for days on feed, ration costs, and cash cattle price may be 160 days, $\$ 150$ per dry ton, and $\$ 80$ per hundredweight live, respectively (American Angus Association, 2007).

\section{Grid Value (\$G)}

Grid Value (\$G) combines both quality grade and yield grade attributes and is calculated for animals with carcass EPDs, ultrasound EPDs or both types of EPDs. In order to reflect reality, a three-year rolling average is used to establish typical industry economic values for quality grade and yield grade. In terms of quality grade, premiums are specific for Prime, $C A B$ and Choice carcasses with Select and Standard grade discounted. In terms of yield grade, premiums are awarded for YG 1 and $Y G 2$ carcasses with discounts for YG 4 
and YG 5 carcasses. The Grid Value formula calculates grid impact in dollars per hundredweight (cwt.), and dollars per head is calculated from the yield and quality grade components. For example, quality grade may contribute $\$ 0.50$ per hundredweight to $\$ \mathrm{G}$ for an 800 pound carcass. Therefore, quality grade contributes four dollars per head $(\$ 0.50 \times 8)$ to Grid Value. In addition, yield grade may contribute $\$ 1.00$ per hundredweight to Grid Value for the same carcass, which equals eight dollars per head $(\$ 1.00 \times 8)$. The addition of the quality and yield grade components then equals twelve dollars for that particular animal.

\section{Beef Value (\$B)}

Beef Value (\$B) combines both Feedlot Value and Grid Value. However, the formula for Beef Value is not a simple addition of these two main components. Also, taken into account in Beef Value are projected carcass weight and its value, production cost differences, and any discount for heavyweight carcasses. Finally, adjustments are made to prevent doublecounting weight between feedlot and carcass segments. Simply, Beef Value projects the difference, in dollars per head, of both feedlot and carcass performance of progeny when compared to progeny of other sires. Beef Value is comprised of many factors representing both feedlot and carcass performance, therefore, it is designed to be a dynamic selection tool for producers. 


\section{Industry Use}

Feedlot Value (\$F), Grid Value (\$G), and Beef Value (\$B) are all indexes that encompass both feedlot and carcass merit. While these factors are significant in terms of beef production, they simply should not be selected on individually. Producers should use these indexes as a means of sorting animals. While Beef Value (\$B) combines both Feedlot Value (\$F) and Grid Value (\$G), it still should not be selected upon individually, as an animal's overall performance is based upon much more than is encompassed in the calculation of Beef Value. 


\section{Materials and Methods}

The objective of this study was to determine the relationships of sale price to EPD, Angus Dollar Value Indexes, and actual measurements among Angus bulls of two different seedstock bull providers. Data were obtained from Gardiner Angus Ranch, Ashland, Kansas, for years 2000-2006 on 819 Angus bulls and from the Wardensville bull test, Wardensville, West Virginia, for years 2001-2005 on 357 Angus bulls. Expected progeny differences (EPD) for birth weight (BW EPD), weaning weight (WW EPD), yearling weight (YW EPD), maternal milk (MM EPD), yearling height (YH EPD), scrotal circumference (SC EPD), intramuscular fat (IMF EPD), ribeye area (REA EPD), and rib fat (RBFT EPD) were obtained along with Angus Dollar Value Indexes for Weaned Calf Value (\$W), Feedlot Value (\$F), Grid Value (\$G), and Beef Value (\$B). Actual measurements for average daily gain (ADG), rump fat (Rmpft), rib fat (Ribft), ribeye area (REA), intramuscular fat (IMF), adjusted yearling weight (AdjYW), and bull sale price were obtained as well. Data from Angus bulls were used because the Angus breed is representative of not only the Wardensville bull test, but also the U.S. beef cattle population. Data from Gardiner Angus Ranch were used as a means of comparison between a state bull test station and an established elite seedstock provider. Not only did the Gardiner Angus Ranch data provide a comparison in terms of genetic merit, but also in terms of sale price, which reflects variables such as genetic merit and customer base.

In part one of data analysis, each bull was ranked as either high or low for each of five categories. The categories chosen were calving ease, growth, 
maternal, carcass, and beef value (growth and carcass) and the variables utilized were Birth Weight EPD (BW EPD), Feedlot Value (\$F), Weaned Calf Value (\$W), Grid Value (\$G), and Beef Value (\$B), respectively. For the calving ease category, Birth Weight EPD was utilized as the logical comparison as it is the most common tool buyers use to distinguish calving ease bulls from non-calving ease bulls. The growth category was chosen because of the importance that is placed upon postweaning gain for both breeding and slaughter animals. Feedlot Value (\$F) is derived from Weaning Weight and Yearling Weight EPD, therefore, it was used to compare the growth category. The maternal category represents an important aspect of the beef industry that cannot be measured or predicted directly. However, Weaned Calf Value (\$W) combines the measurable traits that are most closely related to maternal characteristics (birth weight, weaning weight, maternal milk, and mature cow size). Because satisfying the consumer is a primary goal and carcass quality directly affects eating quality, the carcass category was included. The Grid Value (\$G) index was used to compare bulls in the carcass category as it encompasses intramuscular fat, ribeye area, external fat thickness, and carcass weight by using the data from carcass EPD, ultrasound EPD or both. The final category was termed beef value and is based on the Beef Value $(\$ B)$ index which facilitates multi-trait selection for both postweaning gain and carcass value. These categories were chosen to represent the major aspects of bull selection. Each category was split between high and low groups by the mean for that variable. Differences between high and low groups for each category were then examined by analysis of variance, which 
was performed by the GLM procedure of SAS, using sale price as the dependent variable.

During the initial analysis of variance, few buyer tendencies for the Wardensville bull test were revealed. Because of that, an analysis of variance with more variables included and further division into high, middle, and low groups for some variables was performed. In the more detailed analysis of variance, Weaning Weight EPD (WW EPD), Yearling Weight EPD (YW EPD), Maternal Milk EPD (MM EPD), and actual Average Daily Gain (ADG) were added to the original five variables tested for effects on sale price. All variables in the test were split into upper, middle, and lower one thirds rather than simply high and low groups with the exception of Yearling Weight EPD (YW EPD), Maternal Milk EPD (MM EPD), and actual Average Daily Gain (ADG), which were split into high (above average) and low (below average) groups.

In part three, stepwise analysis of SAS was utilized. Forward and backward elimination as well as stepwise selection procedures were used in order to determine which combination of variables best predicted sale price. 


\section{Results and Discussion}

\section{Part One - Analysis of Variance-}

\section{Results}

For the Gardiner data set, sale price differed significantly between high and low bulls $(P<0.05)$ for Birth Weight EPD, Weaned Calf Value, Grid Value, and Beef Value (see Table 6). The mean Birth Weight EPD was +1.6; therefore, anything above +1.6 was termed high birth weight and anything below was termed low birth weight. There were 375 bulls considered high and 443 considered low for Birth Weight EPD with mean sale prices of $\$ 4591.33$ $(S D=\$ 5451.49)$ and $\$ 4454.29(S D=\$ 2120.86)$, respectively. The maternal category (\$W) was split between high and low groups at $\$ 24.53$. The average price for the 425 high $\$ W$ bulls (\$4885.88; SD=\$5305.29) was significantly greater than for the 393 low $\$$ W bulls $(\$ 4118.32 ; \mathrm{SD}=\$ 1638.58)$. The carcass category, evaluated using the Grid Value $(\$ G)$ index, was split at $\$ 19.72$, with 455 bulls in the high group and 363 bulls in the low group $(P<0.05)$. Average sale prices were $\$ 5208.24$ (SD=\$5158.84) for the high Grid Value group and $\$ 3650.83$ (SD=\$1215.04) for the low group. Finally, the beef value category (\$B) was split at $\$ 41.18$, with 482 high bulls and 336 bulls below average. Average sale price was $\$ 5229.77$ ( $\mathrm{SD}=\$ 5031.63$ ) for high Beef Value bulls and $\$ 3494.79$ $(\mathrm{SD}=\$ 997.28)$ for low Beef Value bulls. 
The growth category was separated into high $(n=424)$ and low $(n=324)$ groups by the Feedlot Value (\$F) mean of $\$ 26.61$. Sale price did not differ significantly due to Feedlot Value. The high Feedlot Value (\$F) bulls received a mean price of $\$ 4741.75$ (SD=\$2629.16) while the low bulls averaged $\$ 4275.38$ $(\mathrm{SD}=\$ 5079.11)$ (see Table 6 and 7).

For the Wardensville data set, sale price differed significantly between high and low bulls only for Beef Value $(P<0.05)$ (see Table 8$)$. When compared to the Gardiner bulls, Birth Weight EPD mean was 0.7 greater at 2.3, Feedlot Value (\$F) was $\$ 12.81$ lower at $\$ 13.80$, Weaned Calf Value ( $\$$ W) was $\$ 1.45$ lower at $\$ 23.08$, Grid Value $(\$ \mathrm{G})$ was $\$ 14.61$ lower at $\$ 12.18$, and Beef Value (\$B) was $\$ 16.47$ lower at $\$ 24.71$ (see Table 8 and 9).

\section{Discussion}

Based upon the analysis of variance, Gardiner bull buyers were willing to pay more for bulls with larger Birth Weight EPD and higher Weaned Calf Values, Grid Values, and Beef Values. On average, buyers paid $\$ 137.04$ more for bulls with Birth Weight EPD above +1.6. Typically, lower Birth Weight EPD tend to be more desirable. However, these data showed that the bulls in the high birth weight category brought more on average. Most likely this outcome is because the Birth Weight EPD average of +1.6 was not only below the current breed average, but also below what most producers think is too high for heifers. In terms of the maternal category, buyers tended, on average, to pay $\$ 767.56$ more for bulls that were above the average of $\$ 24.53$ for Weaned Calf Value. This is 
logical as higher Weaned Calf Values reflect bulls with the potential to increase profit from birth to weaning. There was a large spread in average sale price of bulls in the carcass category. Bulls that were above the average Grid Value of $\$ 19.72$ brought $\$ 1557.41$ more, on average, than bulls below average for Grid Value. It is logical that bulls with potential to transmit carcass quality to their offspring will demand a premium. In the final category of Beef Value, bulls in the high group (over the average of $\$ 41.18$ ) brought $\$ 1734.98$ more than bulls below average for Beef Value (see Table 7). Gardiner bull buyers were obviously willing to pay more for bulls with the potential to increase carcass quality. Sale price was not significant with Feedlot Value. Therefore, buyers did not have a strong tendency to pay more for bulls with greater potential for postweaning gain alone. However, Feedlot Value is one of the major components of Beef Value. Therefore, Feedlot Value must be considered when selecting to increase Beef Value.

Among the four categories with a significant relationship to sale price in the Gardiner bull data, Beef Value had the highest monetary difference between high and low groups (\$1734.98). This is quite a large difference considering the average Gardiner bull sale price in the entire data set was $\$ 4517$. That average was $\$ 2302$ more than the average sale price of Wardensville bulls and $\$ 1482$ more than the average sale price of Angus bulls sold in the entire year of 2005 (see Table 3).

Sale price was influenced significantly by Beef Value in the Wardensville bull data. As stated before, while neither Feedlot Value nor Grid Value 
influenced sale price significantly, they are the two main components of Beef Value. In addition to Beef Value, other means of decision making are, quite possibly, more prevalent in the Wardensville bull test sale. Factors that cannot be measured such as phenotype, pedigree, consignor reputation, and pre-test management techniques were possibly given more emphasis by the buyers of Wardensville Angus bulls.

\section{Part Two - Wardensville Detailed Analysis of Variance-}

\section{Results}

Sale price was influenced significantly $(P<0.05)$ by Yearling Weight EPD (YW EPD), Feedlot Value (\$F), and Weaned Calf Value (\$W) (see Table 10). Yearling Weight EPD (YW EPD) was split into high and low groups at the average of +67 , with 176 bulls considered high and 181 bulls considered low for Yearling Weight EPD (YW EPD). A bull considered high for Yearling Weight EPD (YW EPD) received an average sale price of $\$ 2546.16$ (SD=\$969.58) while a low bull received an average sale price of $\$ 1892.82$ ( $S D=\$ 802.24)$. Feedlot Value (\$F) was segmented into three groups with each group representing one third of the total range. The high group was greater than $\$ 24.17$, the medium group range was between $\$ 6.10$ and $\$ 24.17$, and the low group was less than $\$ 6.09$. The entire range was from $-\$ 11.99$ to $\$ 42.25$. Twenty seven bulls had an average sale price of $\$ 2944.44$ ( $S D=1208.09), 252$ bulls had an average sale price of $\$ 2297.02$ ( $S D=929.58)$, and 78 bulls had an average sale price of 
$\$ 1699.36$ (SD=591.31) in the high, medium, and low groups, respectively. Weaned Calf Value (\$W) was segmented into three groups as well, with each group representing one third of the total range. The range for Weaned Calf Value (\$W) was from $\$ 12.70$ to $\$ 32.74$. The high group was above $\$ 26.02$, the medium group ranged from $\$ 19.39$ to $\$ 26.02$, while the group labeled low consisted of any bull less than $\$ 19.38$. Forty eight bulls had an average sale price of $\$ 2617.70$ ( $S D=917.53), 251$ bulls had an average sale price of $\$ 2212.35$ ( $S D=897.51)$, and 58 bulls had an average sale price of $\$ 1895.69$ ( $S D=1058.93)$ in the high, medium, and low groups, respectively (see Table 11).

\section{Discussion}

Based upon the more detailed analysis of variance for the Wardensville data, bull buyers tended to pay more for bulls with higher Yearling Weight EPD, higher Feedlot Values, and higher Weaned Calf Values. In terms of Yearling Weight EPD, buyers paid $\$ 653.34$ more for bulls that were above the average of +67. For Feedlot Value, bulls in the upper one third brought $\$ 1245.08$ more than bulls in the lower one third and $\$ 647.42$ more than the bulls in the middle one third. Weaned Calf Value had large price differences as well. Bulls in the upper one third brought $\$ 722.01$ more than bulls in the lower one third and $\$ 405.35$ more than bulls in the middle one third (see Table 11). Based upon this more detailed analysis of variance, consignors to the Wardensville bull test could increase their bull sale price most by selling bulls that excel for Yearling Weight EPD, Feedlot Value, and Weaned Calf Value. 


\section{Part Three -Analysis of Variance - Forward Selection-}

\section{Results}

In part three, forward, backward, and stepwise selection procedures were performed in order to determine the best fit model to predict bull sale price for each the Gardiner and Wardensville data set. Beginning with the Gardiner data set, forward selection provided the most logical model to predict bull sale price. Stepwise selection derived the same model as the forward selection procedure, while backward elimination only eliminated variables with $p$-values higher than 0.15 , therefore it was not as precise. Six variables were entered with $P<0.05$. They were actual Rib Fat (Ribft), Adjusted Yearling Weight (AdjYW), Intramuscular Fat EPD (IMF EPD), Ribeye Area EPD (REA EPD), Rib Fat EPD (RBFT EPD), and Weaned Calf Value (\$W). Analysis of variance yielded this formula to predict bull sale price: [Sale price $=$ six year data set price mean coefficient $+0.49($ Ribft $)+0.183($ AdjYW $)+0.263($ IMF EPD $)+0.308(R E A$ EPD $)-$ 0.0083(RBFT EPD) + 0.141(\$W)] (see Table 12).

Forward selection was also the most logical application for the Wardensville data set. Five variables were entered into the model at $\mathrm{P}<0.05$. They were actual Ribeye Area (REA), Adjusted Yearling Weight (AdjYW), Intramuscular Fat EPD (IMF EPD), Ribeye Area EPD (REA EPD), and Beef Value (\$B). Analysis of variance yielded this formula to predict bull sale price: [Sale Price $=$ five year data set price mean coefficient $+0.342(R E A)-$ 0.158(AdjYW) + 0.218(IMF EPD) + 0.169(REA EPD) + 0.362(\$B)] (see Table 13). 


\section{Discussion}

While Beef Value was the variable that had the largest impact on the sale price of Gardiner Angus bulls based on the analysis of variance, it was not added into the forward selection model. However, five of the six variables used in the forward selection model are components of Beef Value. The only variable that was added into the forward selection model that is not used to derive Beef Value was Weaned Calf Value (\$W). Weaned calf value was significant in the analysis of variance; therefore, it is logical that it was added into the forward model.

Wardensville bull buyers tended to prefer heavy muscled, heavy weight bulls with end product merit. Feedlot value was the sixth variable entered into the model at $\mathrm{P}<0.0156$. Though it was significant at $\mathrm{P}<0.05$, its inclusion caused Beef Value becoming insignificant. However, it supported the theory that buyers of Wardensville Angus bulls are willing to pay more for bulls that are growth and efficiency oriented.

\section{Conclusions}

The beef industry is unique when compared to the other meat providers in the United States; it is not vertically integrated. Therefore, each breeder makes his or her own breeding decisions based upon their own preferences. Providers of goods and services must be aware of the preferences of the consumers of their products. The beef industry must communicate well because there are a vast number of people making decisions that influence the beef supply.

There are several key places in the beef supply cycle at which important decisions are made influencing consumer satisfaction. These general areas 
include genetics, nutrition, and management practices. This study focuses on the genetic aspect of decision making. Commercial beef producers make influential decisions every breeding season when they purchase bulls to breed cows. Two Angus bull providers, each from different areas of the United States, were analyzed to determine buyer preferences (Gardiner Angus Ranch in Ashland, Kansas and Wardensville Bull Test in Wardensville, West Virginia). Gardiner Angus Ranch, an elite, family-owned Angus breeder and Wardensville bull test, an established, consignor-based bull alliance allowed the study to focus on contrasting avenues of providing bull genetics into the beef supply chain.

Statistical analysis of measurable traits, predictive of price, tended to produce stronger relationships in the Gardiner data. While the Wardensville bull data did produce significant relationships, the relationships were typically not as strong or as numerous.

Obviously, because the Gardiner data showed significant relationships with bull sale price, Gardiner bull buyers place more emphasis on actual measurements, expected progeny differences, and Angus Dollar Value Indexes when compared to Wardensville bull buyers. Quite possibly, buyers of Wardensville bulls put more emphasis on factors not quantitatively measurable. For example, since the Wardensville bulls are consigned by different breeders, breeder reputation may have a significant impact on bull sale price. Pre-test management of bulls, cow herd management, and individual marketing efforts of each consignor likely influence bull sale price. 
Bull phenotype likely has an impact on bull sale price. The best fit model for the Wardensville bull data showed that actual Ribeye Area, Adjusted Yearling Weight, Intramuscular Fat EPD, Ribeye Area EPD, and Beef Value were the variables significant at the $\mathrm{P}<0.05$ level. These variables, excluding Intramuscular Fat EPD and Beef Value, are closely related to differences between bulls that can be visually appraised. Therefore, the positive relationships with those variables may be influenced by buyers' emphasis on bull phenotype. A survey of bull buyers would likely provide more insight. Another factor not included in each data set was each bull's pedigree. Sire groups quite possibly influence the buying decisions of knowledgeable bull buyers.

The final factor that potentially influences bull sale price among different providers is customer service. Bull guarantees, transportation expenses, and marketing efforts vary immensely among bull providers. The Gardiner Angus Ranch guarantee is specific. It reads:

'We guarantee that all breeding cattle sold by Gardiner Angus Ranch, both bulls and females, are fertile to the best of our knowledge. If a bull is injured at any time in the 12 months following the sale as so to make them functionally infertile, we will provide you with a satisfactory replacement (if available), or issue you a credit equal to the bull's purchase price minus the salvage value received for that bull. All credit is good until it is used and does not expire. We would simply ask you to contact us before you cull your infertile animal. 
This is not a life insurance policy, however. We will not replace a dead animal if it is killed or dies for any reason. We would suggest that normal care still needs to be exercised toward these animals and that particularly the yearling bulls not be allowed to get too thin.

This guarantee is in addition to the Suggested Sale Terms and Conditions of the American Angus Association, which also apply' (www.gardinerangus.com).

In addition to the Gardiner bull guarantee, free shipping to central locations in the United States is offered. Several marketing opportunities also exist through special sales, video auctions, and retained ownership of calves. These services offer much more to customers than simply a bull, and help to ensure that firsttime buyers become repeat customers.

The Wardensville bull test offers useful services as well most notably the introduction of feed efficiency data on each bull using the Grow Safe 4000E system. This system measures residual feed intake (RFI) which is calculated as the difference in expected intake versus actual intake. Residual feed intake offers a selection tool for feed efficiency that is independent of rate of gain and birth weight. This system is relatively new technology that has significance in terms of improving feed efficiency.

The Wardensville bull test offers a bull guarantee as well. It reads as follows, 
'All bulls are guaranteed by the seller if they are properly managed. Any bull that settles one-third of the healthy cows he breeds will be considered a breeder. In the event of non-breeders, the buyer must notify the seller within nine months of the sale date. Any bull that has not proven himself a breeder within nine months of the sale may be returned to the seller at the buyer's expense provided he is in healthy condition and meets the health requirements of the consignor's state of origin. The seller may immediately refund the full purchase price, which is considered as full settlement and satisfaction of all claims, or the seller may attempt for a period not to exceed six months, to prove the bull a breeder. If, after this time, the bull is proven to be a non-breeder, the seller will refund full purchase price. Other settlement procedures may be used if agreed upon by both the buyer and the seller' (West Virginia bull sale catalog).

In addition to the bull guarantee, other services beneficial to buyers exist. In terms of transportation, if you buy a bull for a sale price of $\$ 4000$ or higher, the cost of delivery to a central location will be shared up to $\$ 200$ per bull. As well, bulls can be shipped to one of three locations within West Virginia at a cost of \$20 per head. Marketing opportunities also exist for producers through West Virginia calf pools.

Breeders of seedstock must provide their customers not only reliable genetics, but also reliable service. Both bull providers in this study offer useful services to their customers. Most likely, the services offered influence bull sale 
price. Gardiner bulls, on average, bring more dollars per head. Their bull guarantee and transportation services are more comprehensive as well. Profitable producers are conscientious of risk management. When beef producers buy bulls, they understand the added value of the services that accompany their purchase, and likely are willing to pay more for bulls that come with these services. 


\section{Tables-}

Table 1 - Ultrasound Adjustments for Age and Weight of Angus Bulls and Heifers

Age and weight regressions that can be used to adjust ultrasound measures in yearling Angus bulls and developing heifers (Wilson et al., 2000).

\begin{tabular}{|c|c|c|c|c|c|c|c|c|}
\hline \multirow[b]{2}{*}{ Trait } & \multicolumn{4}{|c|}{ Bulls } & \multicolumn{4}{|c|}{ Heifers } \\
\hline & $\begin{array}{c}\text { Age } \\
\text { b }\end{array}$ & $\mathrm{R}^{2}$ & $\begin{array}{l}\text { Weight } \\
\text { b }\end{array}$ & $\mathrm{R}^{2}$ & $\begin{array}{c}\text { Age } \\
\text { b }\end{array}$ & $\mathrm{R}^{2}$ & $\begin{array}{l}\text { Weight } \\
\text { b }\end{array}$ & $\mathrm{R}^{2}$ \\
\hline $\begin{array}{l}12-13^{\text {th }} \text { rib } \\
\text { fat, in. }\end{array}$ & .000516 & .47 & .000295 & .53 & .00087 & .59 & .00038 & .63 \\
\hline $\begin{array}{l}\text { Rump fat, } \\
\text { in. }\end{array}$ & .000517 & .39 & .000285 & .44 & .00130 & .53 & .00049 & .59 \\
\hline $\begin{array}{l}\text { Ribeye } \\
\text { area, in. }\end{array}$ & .01262 & .51 & .00620 & .61 & .01666 & .54 & .00684 & .63 \\
\hline \%IMF, \% & .00359 & .44 & .00033 & .43 & .00504 & .36 & .00061 & .35 \\
\hline
\end{tabular}




\section{Table 2 - Ultrasound Age of Dam Adjustments for Angus Bulls and Heifers}

Age of dam effects for scanning weight and \% IMF in yearling Angus bulls and developing heifers (Wilson et al., 2000).

\begin{tabular}{|c|ccc|ccc|}
\hline $\begin{array}{c}\text { Age of } \\
\text { Dam } \\
\text { Years }\end{array}$ & $\begin{array}{c}\text { No. of Bull } \\
\text { Progeny }\end{array}$ & \%IMF, \% & $\begin{array}{c}\text { Scannina } \\
\text { Weight, Ibs. }\end{array}$ & $\begin{array}{c}\text { No. of } \\
\text { Heifer } \\
\text { Progeny }\end{array}$ & \%lMF,\% & $\begin{array}{c}\text { Scanning } \\
\text { Weight, Ibs. }\end{array}$ \\
\hline$<=2$ & 5237 & .094 & 73.24 & 1746 & .13 & 46.82 \\
3 & 4246 & .034 & 33.66 & 1305 & .12 & 25.62 \\
4 & 3562 & .00 & 12.23 & 1198 & .02 & 9.98 \\
5 & 3175 & -.02 & .72 & 887 & .03 & .64 \\
6 & 2544 & 0 & 0 & 682 & 0 & 0 \\
7 & 2067 & .02 & 1.70 & 570 & -.03 & 2.28 \\
8 & 1599 & -.03 & 5.86 & 418 & .06 & 8.10 \\
9 & 1044 & -.01 & $14.29(11.0)^{2}$ & 328 & -.02 & $13.85(13.0)$ \\
10 & 671 & -.08 & 18.40 & 183 & .11 & 15.49 \\
11 & 534 & -.07 & $22.80(28.0)$ & 143 & -.10 & $28.52(26.0)$ \\
$12+$ & 696 & -.06 & 40.59 & 237 & -.07 & 34.23 \\
\hline
\end{tabular}

${ }^{1}$ Age of dam at progeny scanning time.

${ }^{2}$ Numbers in parentheses are curve fitting numbers. That is, numbers to keep the adjustments following a smooth curve as age increases. Low numbers cause some of the older age of dam categories and their resulting adjustment factors to be slightly erratic in nature. 
Table 3 -- Average Angus Bull Comparisons

\begin{tabular}{|c|cccccccccccc|}
\hline EPD & BW & WW & YW & Milk & YH & SC & $\%$ IMF & REA & \$W & \$F & \$G & \$B \\
\hline $\begin{array}{l}\text { Wardensville } \\
\text { Average Bull }\end{array}$ & 2.3 & 38 & 70 & 20 & 0.45 & 0.2 & 0.03 & 0.11 & 23.08 & 13.80 & 12.18 & 24.71 \\
GAR Average Bull & 1.6 & 43 & 84 & 24 & 0.32 & 0 & 0.26 & 0.38 & 24.53 & 26.61 & 19.72 & 41.18 \\
$\begin{array}{c}\text { Angus AVG } \\
\text { (Non-Parent Bull) }\end{array}$ & 2.3 & 40 & 74 & 19 & 0.4 & 0.3 & 0.13 & 0.22 & 23.48 & 19.07 & 14.61 & 32.28 \\
\hline
\end{tabular}

\begin{tabular}{|c|c|c|c|c|c|}
\hline Act. Measurement & ADG & \%IMF & REA & ADJYW & Price \\
\hline Wardensville & & & & & \\
\hline Average Bull & 4.36 & 4.08 & 13.8 & 1233 & $\$ 2,215$ \\
\hline GAR Average Bull & 5.23 & 4.74 & 13.7 & 1199 & $\$ 4,517$ \\
\hline
\end{tabular}

*The average bull sale price for the entire Angus breed in 2005 was \$3,035 (www.angus.org) 
Table 4 - Gardiner Angus Bull Data - Simple Statistics

\begin{tabular}{|c|c|c|c|c|c|c|}
\hline Variable & $\mathrm{N}$ & Mean & SD & Sum & Minimum & Maximum \\
\hline CED & 816 & 7.80392 & 3.07546 & 6368 & -7.00 & 16.00 \\
\hline BW EPD & 819 & 1.64359 & 1.31148 & 1346 & -2.80 & 6.20 \\
\hline WW EPD & 819 & 42.59096 & 5.75137 & 34882 & 18 & 62 \\
\hline YW EPD & 819 & 84.15018 & 8.64588 & 68919 & 52 & 112 \\
\hline YH EPD & 814 & 0.32494 & 0.22627 & 264.50 & -0.50 & 1.10 \\
\hline SC EPD & 805 & 0.03596 & 0.40756 & 28.95 & -1.15 & 1.25 \\
\hline CEM EPD & 816 & 8.27941 & 1.91868 & 6756 & -2.00 & 13.00 \\
\hline Maternal Milk EPD & 819 & 24.28449 & 5.28812 & 19889 & 9 & 40 \\
\hline IMF EPD & 819 & 0.25698 & 0.18731 & 210.47 & -0.25 & 0.85 \\
\hline REA EPD & 818 & 0.38416 & 0.25327 & 314.24 & -0.46 & 1.16 \\
\hline RBFT EPD & 819 & 0.00747 & 0.01182 & 6.11500 & -0.035 & 0.048 \\
\hline \$EN & 819 & 1.13420 & 5.02519 & 928.91 & -11.12 & 19.50 \\
\hline$\$ W$ & 819 & 24.53346 & 2.85417 & 20093 & 12.77 & 33.35 \\
\hline$\$ F$ & 819 & 26.60590 & 6.74003 & 21790 & 3.16 & 47.71 \\
\hline$\$ G$ & 819 & 19.72182 & 5.87499 & 16152 & 3.19 & 34.42 \\
\hline$\$ B$ & 819 & 41.18136 & 7.49154 & 33728 & 8.36 & 57.43 \\
\hline ADG & 819 & 5.22746 & 0.93660 & 4281 & 2.91 & 7.69 \\
\hline Rump fat & 816 & 0.37056 & 0.08316 & 302.38 & 0.18 & 0.71 \\
\hline Rib fat & 818 & 0.32834 & 0.07714 & 268.58 & 0.14 & 0.73 \\
\hline Actual REA & 816 & 13.72096 & 1.60496 & 11196 & 9.10 & 18.50 \\
\hline Actual IMF & 817 & 4.73540 & 1.27011 & 3869 & 2.26 & 9.53 \\
\hline Adjusted YW & 819 & 1199 & 91.94042 & 982258 & 897.00 & 1486 \\
\hline Sale Price (\$) & 819 & 4,517 & 4,003 & $3,699,750$ & 2,000 & 90,000 \\
\hline
\end{tabular}


Table 5 - Wardensville Angus Bull Data - Simple Statistics

\begin{tabular}{|c|c|c|c|c|c|c|}
\hline Variable & $\mathrm{N}$ & Mean & SD & Sum & Minimum & Maximum \\
\hline BW EPD & 357 & 2.49916 & 1.34450 & 892.20 & -1.30 & 6.30 \\
\hline WW EPD & 357 & 35.93557 & 5.80283 & 12829 & 22 & 56 \\
\hline YW EPD & 356 & 67.37360 & 9.43134 & 23985 & 45 & 101 \\
\hline YH EPD & 269 & 0.48030 & 0.20774 & 129.20 & 0 & 1.00 \\
\hline SC EPD & 284 & 0.17908 & 0.28858 & 50.86 & -0.53 & 1.18 \\
\hline Maternal Milk EPD & 357 & 19.12885 & 3.62888 & 6829 & 7 & 29 \\
\hline IMF EPD & 353 & 0.00873 & 0.09247 & 3.08 & -0.23 & 0.39 \\
\hline REA EPD & 353 & 0.08686 & 0.14346 & 30.66 & -0.38 & 0.47 \\
\hline RBFT EPD & 353 & 0.00376 & 0.01406 & 1.329 & -0.031 & 0.064 \\
\hline$\$ W$ & 357 & 22.48482 & 3.07916 & 8027 & 12.70 & 32.74 \\
\hline$\$ F$ & 357 & 11.75619 & 8.16714 & 4197 & -11.99 & 42.25 \\
\hline$\$ G$ & 355 & 11.30575 & 4.91671 & 4014 & -1.26 & 26.86 \\
\hline$\$ B$ & 355 & 22.25986 & 8.17540 & 7902 & -0.67 & 41.60 \\
\hline ADG & 284 & 4.36218 & 0.45397 & 1239 & 2.92 & 5.76 \\
\hline Rump Fat & 237 & 0.41000 & 0.09732 & 97.17 & 0.20 & 0.74 \\
\hline Rib Fat & 351 & 0.38729 & 0.10598 & 135.94 & 0.16 & 0.74 \\
\hline Actual REA & 351 & 13.36382 & 1.24323 & 4691 & 9.50 & 17.10 \\
\hline Actual IMF & 351 & 3.93085 & 0.72318 & 1380 & 2.39 & 7.08 \\
\hline Adjusted YW & 352 & 1240 & 90.56578 & 436328 & 887.00 & 1506 \\
\hline Sale Price (\$) & 357 & 2215 & 945.96 & 790,900 & 1,000 & 6,100 \\
\hline
\end{tabular}


Table 6 - Analysis of Variance - Gardiner Data

Dependent Variable: Sale price

\begin{tabular}{llllll} 
Source & DF & $\begin{array}{c}\text { Sum of } \\
\text { Squares }\end{array}$ & Mean Square & F Value & $\operatorname{Pr}>$ F \\
\hline Model & 5 & 895830347 & 179166069 & 11.91 & $<.0001$ \\
Error & 812 & 12210930045 & 15038091 & & \\
Corrected Total & 817 & 13106760391 & & & \\
\hline
\end{tabular}

\begin{tabular}{llll} 
R-Square & Coefficient Variable & Root MSE & Price Mean \\
\hline 0.068349 & 85.84900 & 3877.898 & $\$ 4517.115$ \\
\hline
\end{tabular}

\begin{tabular}{llllll} 
Source & DF & Type III SS & Mean Square & F Value & Pr $>$ F \\
\hline BW EPD & 1 & 63703349.7 & 63703349.7 & 4.24 & $\mathbf{0 . 0 3 9 9}$ \\
\$F & 1 & 17775779.3 & 17775779.3 & 1.18 & 0.2773 \\
\$W & 1 & 185098305.0 & 185098305.0 & 12.31 & $\mathbf{0 . 0 0 0 5}$ \\
\$G & 1 & 116836519.8 & 116836519.8 & 7.77 & $\mathbf{0 . 0 0 5 4}$ \\
\$B & 1 & 156579839.9 & 156579839.9 & 10.41 & $\mathbf{0 . 0 0 1 3}$ \\
\hline
\end{tabular}


Table 7 - Analysis of Variance - Price Categories - Gardiner Data

\begin{tabular}{|c|c|c|c|}
\hline \multirow[b]{2}{*}{ BW EPD } & \multirow[b]{2}{*}{$\mathrm{N}$} & \multicolumn{2}{|c|}{ Price } \\
\hline & & Mean $(\$)$ & SD (\$) \\
\hline High & 375 & 4591.33 & 5451.49 \\
\hline Low & 443 & 4454.29 & 2120.86 \\
\hline \multicolumn{4}{|l|}{$\$ F$} \\
\hline High & 424 & 4741.75 & 2629.16 \\
\hline Low & 394 & 4275.38 & 5079.11 \\
\hline \multicolumn{4}{|l|}{$\$ W$} \\
\hline High & 425 & 4885.88 & 5305.29 \\
\hline Low & 393 & 4118.32 & 1638.58 \\
\hline \multicolumn{4}{|l|}{$\$ G$} \\
\hline High & 455 & 5208.24 & 5158.84 \\
\hline Low & 363 & 3650.83 & 1215.04 \\
\hline \multicolumn{4}{|l|}{$\$ B$} \\
\hline High & 482 & 5229.77 & 5031.63 \\
\hline Low & 336 & 3494.79 & 997.28 \\
\hline
\end{tabular}


Table 8 - Analysis of Variance - Wardensville Data

Dependent Variable: Sale price

\begin{tabular}{lcllll} 
Source & DF & $\begin{array}{l}\text { Sum of } \\
\text { Squares }\end{array}$ & Mean Square & F Value & $\operatorname{Pr}>$ F \\
\hline Model & 5 & 37137861.8 & 7427572.4 & 9.26 & $<.0001$ \\
Error & 351 & 281427404.3 & 801787.5 & & \\
Corrected Total & 356 & 318565266.1 & & & \\
\hline
\end{tabular}

\begin{tabular}{llll} 
R-Square & Coefficient Variable & Root MSE & Price Mean \\
\hline 0.116579 & 40.41814 & 895.4259 & $\$ 2215.41$ \\
\hline
\end{tabular}

\begin{tabular}{llllll} 
Source & DF & Type III SS & Mean Square & F Value & $\operatorname{Pr}>F$ \\
\hline BW EPD & 1 & 84670.16 & 84670.16 & 0.11 & 0.7454 \\
\$F & 1 & 2935263.79 & 2935263.79 & 3.66 & 0.0565 \\
\$W & 1 & 2171466.46 & 2171466.46 & 2.71 & 0.1007 \\
\$G & 1 & 178206.91 & 178206.91 & 0.22 & 0.6376 \\
\$B & 1 & 11509712.50 & 11509712.50 & 14.36 & $\mathbf{0 . 0 0 0 2}$ \\
\hline
\end{tabular}

*bold indicates significance at $P<0.05$ 
Table 9-Analysis of Variance - Price Categories - Wardensville Data

\begin{tabular}{llll}
\hline BW EPD & $\mathrm{N}$ & Mean $(\$)$ & Price \\
\hline High & 199 & 2234.17 & 1020.47 \\
Low & 158 & 2191.77 & 845.44 \\
\$F & & & \\
High & 134 & 2516.04 & 1017.77 \\
Low & 223 & 2034.75 & 852.68 \\
\$W & & & \\
High & 157 & 2334.08 & 907.43 \\
Low & 200 & 2122.25 & 967.21 \\
\$G & & & \\
High & 151 & 2256.29 & 1002.97 \\
Low & 206 & 2185.44 & 903.21 \\
\$B & & & \\
High & 145 & $\mathbf{2 5 7 0 . 3 4}$ & $\mathbf{1 0 2 5 . 3 5}$ \\
Low & $\mathbf{2 1 2}$ & $\mathbf{1 9 7 2 . 6 4}$ & $\mathbf{8 0 4 . 0 5}$ \\
& & & *bold indicates significance at $P<0.05$
\end{tabular}


Table 10 - Detailed Analysis of Variance - Wardensville Data

Dependent variable: Sale price-

\begin{tabular}{lclccc} 
Source & DF & $\begin{array}{l}\text { Sum of } \\
\text { Squares }\end{array}$ & Mean Square & F Value & Pr $>$ F \\
\hline Model & 15 & 69740230.0 & 4649348.7 & 6.37 & $<.0001$ \\
Error & 341 & 248825036.1 & 729692.2 & & \\
Corrected Total & 356 & 318565266.1 & & & \\
\hline
\end{tabular}

\begin{tabular}{llll} 
R-Square & Coefficient Variable & Root MSE & Price Mean \\
\hline 0.218920 & 38.55818 & 854.2202 & $\$ 2215.41$ \\
\hline
\end{tabular}

\begin{tabular}{lcllll} 
Source & DF & Type III SS & Mean Square & F Value & $\operatorname{Pr}>$ F \\
\hline BW EPD & 2 & 363793.111 & 181896.556 & 0.25 & 0.7795 \\
WW EPD & 2 & 1640277.311 & 820138.656 & 1.12 & 0.3262 \\
YW EPD & 1 & 8249598.855 & 8249598.855 & 11.31 & $\mathbf{0 . 0 0 0 9}$ \\
Maternal Milk EPD & 1 & 863384.079 & 863384.079 & 1.18 & 0.2775 \\
ADG & 1 & 59862.268 & 59862.268 & 0.08 & 0.7747 \\
\$F & 2 & 9167822.913 & 4583911.457 & 6.28 & $\mathbf{0 . 0 0 2 1}$ \\
\$W & 2 & 6121005.602 & 3060502.801 & 4.19 & $\mathbf{0 . 0 1 5 9}$ \\
\$G & 2 & 733579.302 & 366789.651 & 0.50 & 0.6054 \\
\$B & 2 & 639720.893 & 319860.446 & 0.44 & 0.6455 \\
\hline
\end{tabular}

*bold indicates significance at $P<0.05$ 
Table 11 - Detailed Analysis of Variance - Price Categories - Wardensville Data

\begin{tabular}{|c|c|c|c|}
\hline \multirow[b]{2}{*}{ BW EPD } & \multicolumn{3}{|c|}{ Price } \\
\hline & $\mathrm{N}$ & Mean (\$) & SD (\$) \\
\hline High & 112 & 2176.79 & 1012.29 \\
\hline Low & 103 & 2177.67 & 820.719 \\
\hline Medium & 142 & 2273.24 & 979.689 \\
\hline \multicolumn{4}{|l|}{ WW EPD } \\
\hline High & 80 & 2471.25 & 968.48 \\
\hline Low & 78 & 1823.72 & 769.83 \\
\hline Medium & 199 & 2266.08 & 956.42 \\
\hline \multicolumn{4}{|l|}{ YW EPD } \\
\hline High & 176 & 2547.16 & 969.58 \\
\hline Low & 181 & 1892.82 & 802.24 \\
\hline \multicolumn{4}{|l|}{ MM EPD } \\
\hline High & 171 & 2417.84 & 1046.99 \\
\hline Low & 186 & 2029.30 & 801.22 \\
\hline \multicolumn{4}{|l|}{ ADG } \\
\hline High & 153 & 2241.50 & 1054.45 \\
\hline Low & 204 & 2195.83 & 857.82 \\
\hline \multicolumn{4}{|l|}{$\$ F$} \\
\hline High & 27 & $\$ 2944.44$ & $\$ 1208.09$ \\
\hline Low & 78 & 1699.36 & 591.31 \\
\hline Medium & 252 & 2297.02 & 929.58 \\
\hline \multicolumn{4}{|l|}{$\$ W$} \\
\hline High & 48 & 2617.71 & 917.53 \\
\hline Low & 58 & 1895.69 & 1058.93 \\
\hline Medium & 251 & 2212.35 & 897.51 \\
\hline \multicolumn{4}{|l|}{$\$ G$} \\
\hline High & 44 & 2490.91 & 1190.97 \\
\hline Low & 97 & 2015.46 & 829.48 \\
\hline Medium & 216 & 2249.07 & 925.25 \\
\hline \multicolumn{4}{|l|}{$\$ B$} \\
\hline High & 101 & 2650.99 & 1061.04 \\
\hline Low & 63 & 1714.29 & 579.66 \\
\hline Medium & 193 & 2151.04 & 882.02 \\
\hline
\end{tabular}




\section{Table 12 - Analysis of Variance - Forward Selection - Gardiner Data}

R-Square $=0.1647$ and $C(p)=8.2645$

\begin{tabular}{llllll} 
Source & DF & $\begin{array}{l}\text { Sum of } \\
\text { Squares }\end{array}$ & $\begin{array}{l}\text { Mean } \\
\text { Square }\end{array}$ & F Value & Pr $>$ F \\
\hline Model & 6 & 2140715072 & 356785845 & 25.90 & $<.0001$ \\
Error & 788 & 10856526595 & 13777318 & & \\
Corrected Total & 794 & 12997241667 & & & \\
\hline
\end{tabular}

\begin{tabular}{llllll} 
Variable & $\begin{array}{l}\text { Parameter } \\
\text { Estimate }\end{array}$ & $\begin{array}{l}\text { Standard } \\
\text { Error }\end{array}$ & Type II SS & F Value & Pr $>$ F \\
\hline Intercept & -11410 & 2233.02833 & 359735436 & 26.11 & $<.0001$ \\
Rib fat & 4860.53213 & 2425.51216 & 55325508 & 4.02 & 0.0454 \\
ADJ YW & 5.84050 & 1.57251 & 190054337 & 13.79 & 0.0002 \\
IMF EPD & 4296.08968 & 763.76803 & 435901541 & 31.64 & $<.0001$ \\
REA EPD & 3189.81387 & 571.59012 & 429067809 & 31.14 & $<.0001$ \\
Rib Fat EPD & -47528 & 15300 & 132945932 & 9.65 & 0.0020 \\
\$W & 218.84431 & 47.77433 & 289098561 & 20.98 & $<.0001$ \\
\hline
\end{tabular}

Sale Price Model:

Sale price $=-11410+4860.53($ Ribft $)+5.84($ AdjYW $)+4296.09($ IMF EPD $)+$ 3189.81(REA EPD) - 47528(RBFT EPD) + 218.84(\$W) 
Table 13 - Analysis of Variance- Forward Selection - Wardensville Data

R-Square $=0.4740$ and $C(p)=7.1975$

\begin{tabular}{llllll} 
Source & DF & $\begin{array}{l}\text { Sum of } \\
\text { Squares }\end{array}$ & $\begin{array}{l}\text { Mean } \\
\text { Square }\end{array}$ & F Value & Pr $>$ F \\
\hline Model & 6 & 87306840 & 14551140 & 16.67 & $<.0001$ \\
Error & 111 & 96869008 & 872694 & & \\
Corrected Total & 117 & 184175847 & & & \\
\hline
\end{tabular}

\begin{tabular}{llllll} 
Variable & $\begin{array}{l}\text { Parameter } \\
\text { Estimate }\end{array}$ & $\begin{array}{l}\text { Standard } \\
\text { Error }\end{array}$ & Type II SS & F Value & Pr $>$ F \\
\hline Intercept & -1125.17092 & 1803.17159 & 339801 & 0.39 & 0.5339 \\
REA & 542.09734 & 113.36157 & 19956516 & 22.87 & $<.0001$ \\
ADJ YW & -3.93294 & 1.01825 & 13019236 & 14.92 & 0.0002 \\
IMF EPD & 2928.10085 & 995.37050 & 7552042 & 8.65 & 0.0040 \\
REA EPD & -2467.07319 & 948.57506 & 5903133 & 6.76 & 0.0106 \\
\$F & 38.63092 & 15.72667 & 5265728 & 6.03 & 0.0156 \\
\$B & 26.61149 & 16.75108 & 2202494 & 2.52 & 0.1150 \\
\hline
\end{tabular}

Sale Price Model:

Sale Price $=-1125.17+542.10(R E A)-3.93($ ADJYW $)+2928.10($ IMF EPD $)-$ 2467.07(REA EPD) + 38.63(\$F) + 26.61(\$B) 


\section{Works Cited-}

Anderson, D. C., and R. A. Bellows. 1967. Some causes of neonatal and postnatal calf losses. Journal of Animal Science. 26:941.

American Angus Association. 2007. National Angus Cattle Evaluation. [online]. www.angus.org.

Arnold, J. W., J. K. Bertrand, L. L. Benyshek and C. Ludwig. 1991. Estimates of genetic parameters for live animal ultrasound, actual carcass data, and growth traits in beef cattle. Journal of Animal Science. 69: 985-992.

Brown, Jr., A. H., J. J. Chewning, Z. B. Johnson, W. C. Loe, C. J. Brown. 1990. Effects of 84-, 112- and 140-day postweaning feedlot performance tests for beef bulls. University of Arkansas, Fayetteville.

Burdine, K., J.T. Johns, W.B. Mikel. 2002. Understanding Beef Carcass Data Reports. Kentucky Cooperative Extension Service.

Chvosta, J., R.R. Rucker, M.J. Watts. 2001. Transaction Costs and Cattle Marketing: The Information Content of Seller-Provided Presale Data at Bull Auctions. American Journal of Agricultural Economics. 83:286.

Elmore, R. G., C. J. Bierchwal, C. E. Martin and R. S. Youngquist. 1975. A summary of 1127 breeding soundness examinations in beef bulls.

Theriogenology 3:209-218.

Ferrell, C.L., T.G. Jenkins. 1985. Energy Utilization by Hereford and Simmental Males and Females. Animal Production. 41:53-61.

Fox, D. G., L. O. Tedeschi, and P. J. Guiroy. 2001. Determining Feed Intake and Feed Efficiency of Individual Cattle Fed in Groups. Pages 80-98 in Beef Improvement Federation, San Antonio, TX.

Gardiner Angus Ranch. [online]. www.angus.org.

Greiner, S.P. 2002. Understanding Expected Progeny Differences (EPDs). Virginia Tech, Publication Number 400-804.

Gutie'rrez, J. P., F. Goyache, I. Ferna'ndez, I. Alvarez, L. J. Royo. 2007. Genetic relationships among calving ease, calving interval, birth weight, and weaning weight in the Asturiana de los Valles beef cattle breed. Journal of Animal Science. 85:69-75. 
Johnson, C.R., D.L. Lalman, M.A. Brown, L.A. Appeddu, D.S. Buchanan, R.P. Wettemann. 2003. Influence of Milk Production on Potential Forage Dry Matter Intake by Multiparous and Primiparous Brangus Females. Journal of Animal Science. 81:1837-1846.

Koch, R. M., L. V. Cundiff, K. E. Gregory. 1994. Cumulative Selection and Genetic Change for Weaning or Yearling Weight or for Yearling Weight Plus Muscle Score in Hereford Cattle. Journal of Animal Science. 72:864-885. Lamb, R.L., Beshear, M. 1998. From the Plains to the Plate: Can the Beef Industry Regain Market Share? Federal Reserve Bank of Kansas City. Economic review.

Lamb, M.A., O.W. Robinson, M.W. Tess. 1990. Genetic Parameters for Carcass Traits in Hereford Bulls. Journal of Animal Science. 68:64-69.

Laster, D.B., H.A. Glimp, L.V. Cundiff, K.E. Gregory. 1973. Factors Affecting Dystocia and the Effects of Dystocia on Subsequent Reproduction in Beef Cattle. Journal of Animal Science. 36:695-705.

Lorenzen, C.L., D.S. Hale, D.B. Griffin, J.W. Savell, K.E. Belk, T.L. Frederick, M.F. Miller, T.H. Montgomery, G.C. Smith. 1993.

National Beef Quality Audit: Survey of Producer-related Defects and Carcass Quality and Quantity Attributes. Journal of Animal Science. 71:1495-1502.

Marshall, D.M. 1994. Breed Differences and Genetic Parameters for Body Composition Traits in Beef Cattle. Journal of Animal Science. 72:2745-2755.

Moser, D.W., J.K. Bertrand, L.L. Benyshek, M.A. McCann, and T.E. Kiser. 1996. Effects of Selection for Scrotal Circumference in Limousin Bulls on Reproductive and Growth Traits of Progeny. Journal of Animal Science. 74:2052-2057.

National Agricultural Statistics Service. February 2007. Farms, Land in Farms, and Livestock Operations 2006 Summary Agricultural Statistics Board. United States Department of Agriculture.

National Beef Cattle Evaluation Consortium. 2000. Beef Sire Selection Manual.

National Beef Quality Audit. 2000. National Cattlemen's Beef Association.

National Beef Quality Audit: A New Benchmark for the U. S. Beef Industry. 2005. National Cattlemen's Beef Association.

Neely, T.R., C. L. Lorenzen, R. K. Miller, J. D. Tatum, J. W. Wise, J. F. Taylor, M. J. Buyck, J. O. Reagan, J. W. Savell. 1998. Beef Customer Satisfaction: Role of 
Cut, USDA Quality Grade, and City on In-home Consumer Ratings. Journal of Animal Science. 76:1027-1033.

Nugent, R. A., D. R. Notter, W. E. Beal. 1991. Body Measurements of Newborn Calves and Relationship of Calf Shape to Sire Breeding Values for Birth Weight and Calving Ease. Journal of Animal Science. 69:2413- 2421.

Purcell, W.D. 1998. Measures of Changes in Demand for Beef, Pork, and Chicken, 1975-1998. Research Institute on Livestock Pricing.

Sweeter, K. K., D. M. Wulf, R. J. Maddock. 2005. Determining the optimum beef longissimus muscle size for retail consumers. Journal of Animal Science. 83:2598-2604.

Wardensville Bull Test. [online]. www.wvbeef.org/wbt/wbt.html.

Wilson, D.E., G.H. Rouse, C. Hays. 2000. Adjustment Factors for Ultrasound Measures in Yearling Angus Bulls and Developing Heifers. 2000 Beef Research Report - lowa State University. A.S. Leaflet R1714.

Wilson, D.E., R.L. Willham, S.L. Northcutt, G.H. Rouse. 1993. Genetic Parameters for Carcass Traits Estimated from Angus Field Records. Journal of Animal Science. 71:2365-2370. 